\title{
Anesthetic Effect and Physiological Response in Olive Flounder (Paralichthys olivaceus) to Clove Oil in a Simulated Transport Experiment
}

\author{
Hyun Woo Gil' ${ }^{2}$, Min Gyun Ko ${ }^{1}$, Tae Ho Lee ${ }^{2}$, In-Seok Park² and ${ }^{\dagger}$ Dong Soo Kim \\ ${ }^{I}$ Institute of Marine Living Modified Organism (iMLMO), Pukyung National University, Busan 608-737, Korea \\ ${ }^{2}$ Division of Marine Bioscience, College of Ocean Science and Technology, Korea Maritime and Ocean University, \\ Busan 606-791, Korea
}

\begin{abstract}
The optimum concentrations of clove oil as an anesthetic for olive flounder (Paralichthys olivaceus) and the stress response of the fish to clove oil anesthesia were determined over a range of water temperatures, and investigated in a simulated transport experiment using analysis of various water and physiological parameters. While the time for induction of anesthesia decreased significantly as both the concentration of clove oil and water temperature increased, the recovery time increased significantly $(P<0.05)$. The plasma cortisol concentration in fish at each temperature increased significantly up to 12 $\mathrm{h}$ following exposure $(P<0.05)$, then decreased to $48 \mathrm{~h}(P<0.05)$. The DO dissolved oxygen concentrations, $\mathrm{pH}$ values, and the fish respiratory frequencies decreased over $6 \mathrm{~h}$ following exposure to clove oil in all experimental groups $(P<0.05)$, whereas the $\mathrm{NH}_{4}{ }_{4}$ and $\mathrm{CO}_{2}$ concentrations in all experimental groups increased up to $6 \mathrm{~h}(P<0.05)$. The $\mathrm{pH}$ values and DO concentrations increased with increasing clove oil concentration $(P<0.05)$ in the $6 \mathrm{~h}$ following exposure, and the $\mathrm{CO}_{2}$ and $\mathrm{NH}_{4}{ }^{+}$concentrations and the respiratory frequencies decreased with increasing clove oil concentration $(P<0.05)$. The results of this experiment suggest that clove oil reduced the metabolic activity of olive flounder, thus reducing $\mathrm{NH}_{4}{ }^{+}$excretion and $\mathrm{O}_{2}$ consumption. In conclusion, clove oil appears to be a cost-effective and efficient anesthetic that is safe for use and non-toxic to the fish and users. Its use provides the potential for improved transportation of olive flounder.
\end{abstract}

Key words : Anesthetic, Clove oil, Olive flounder, Paralichthys olivaceus, Stress response, Water parameters, Water temperature

\section{INTRODUCTION}

Olive flounder, Paralichthys olivaceus has a flattened oval body, mainly occurs at the benthos in water depths of 10-200 m, and is widely distributed in Korea and East Asia (Han et al., 2007). It is the most important cultured fish in Korea, with approximately 40,922 tons of this species having been produced in 2012 (Park et al., 2012; Park et al., 2015); correspondingly large nursery and transport processes are associated with the mass culture of olive flounder (Hur et al., 2007; Park et al., 2012; Park et al., 2015). However, the lack of knowledge of the physiological changes that occur in the olive flounder during transport has resulted in large mortalities. Olive flounder produced at Jeju Island, Korea, are transported predominantly by truck and ship, and the temperature and dissolved oxygen concentration are controlled during the sometimes long transport period by pumping air, and adding liquefied

\footnotetext{
Manuscript received August 03, 2016, Received in revised form August 19, 2016, Accepted September 20, 2016

${ }^{\dagger}$ Corresponding Author : Dong Soo Kim, Institute of Marine Living Modified Organism (iMLMO), Pukyung National University, Busan 608-737, Korea. Tel : +82-51-629-7066, Fax : +82-51-629-7067, E-mail : dongskim@pknu.ac.kr

This is an Open Access article distributed under the terms of the Creative Commons Attribution Non-Commercial License (http:// creativecommons.org/licenses/by-nc/3.0) which permits unrestricted non-commercial use, distribution, and reproduction in any medium, provided the original work is properly cited.
} 
oxygen and ice to improve fish survival.

To minimize stress and reduce the chance of fish mass mortality (Ferreira et al., 1984) during handling and long periods of transportation, an effective high-density transport method is essential to reduce costs and minimize losses (Ferreira et al., 1984; Staurnes et al., 1994). The development of new equipment and transport procedures is having a positive effect on the transportation of live fish. For example, the use of non-toxic salt has been shown to reduce stress and result in higher survival rates (Tomasso et al., 1980; Carmichael et al., 1984; Carmichael \& Tomasso, 1988), and the use of low concentrations of calcium chloride is also a cheap and effective improvement in the handling and transportation of live fish (Grizzle et al., 1985; Carmichael \& Tomasso, 1988).

The use of anesthetics is also an effective procedure for transporting fish (Park et al., 2009a). Anesthetic use in aquaculture reduces fish energy use, enables efficient transportation, increases ease of handling when measurements are taken, reduces pain and trauma for the fish, reduces handling stress (Park et al., 2009b), and reduces bacterial infections, especially during surgery. Water-temperatureinduced anesthesia, which is recognized as stable in fish, can be used without a mandatory period of withdrawal prior to human consumption, as is required for chemical anesthetics (Summerfelt \& Smith, 1990). The mode of application as well as any local regulations and legislation dictate the choice of anesthetic. Currently, only tricaine methanesulfonate (MS-222) and metomidate are registered for veterinary use in fish, although researchers have access to many other compounds not available for public use (Park et al., 2011). Lengthy withdrawal periods are mandatory for chemical anesthesia of food fish prior to harvest, and this has led to an interest in the search for less persistent and more natural anesthetics; among these is clove oil (Park et al., 2011).

The active ingredient in clove oil is eugenol (4-allyl-2- methoxyphenol), which is inexpensive and a safe anesthetic that has been used as a substitute for commonly used compounds including MS-222 (Park et al., 2011). Compared with MS-222, clove oil is characterized by more rapid induction of anesthetic effects, prolonged recovery times, and a narrower range of safe doses in at least three teleost species (Sladky et al., 2001). Clove oil is also safe, inexpensive, and non-toxic for the environment, and does not require a withdrawal period compared with other anesthetic chemicals (Park et al., 2008). Clove oil has been studied as an anesthetic in a number of species (Park et al., 2011).

The aim of this study was to determine the optimum concentrations of clove oil for anesthesia in olive flounder over a range of temperature conditions. Stress responses in the fish and water parameters were also analyzed during a simulated transport experiment involving various clove oil concentrations.

\section{MATERIALS AND METHODS}

In March 2016, specimens of olive flounder, Paralichthys olivaceus (Standard length: $46.6 \pm 0.45 \mathrm{~cm}$; Body weight: $500.7 \pm 11.67 \mathrm{~g}$ ), were obtained from the Institute of Marine Living Modified Organisms, Pukyung National University, Korea. The fish were transported to the Fishery Genetics and Breeding Sciences Laboratory of the Korea Maritime and Ocean University, Korea, and reared in a recirculating culture system consisting of a circulation pump, an aeration system, and a temperature control system. The temperature of the water in the tube were controlled so that it was equal to the temperature of the water in the anesthetic and recovery phases of the experiment. The water temperature of each tube were maintained by heater. All fish were fasted for $24 \mathrm{~h}$ prior to the commencement of experiments, and were adapted to $400-\mathrm{L}$ glass tubes, which were maintained at the same temperatures as the experimental water tempeatures $\left(15,20\right.$, and $\left.25^{\circ} \mathrm{C}\right)$. 
For the anesthetic experiment, 20 specimens of each experimental group were randomly removed from the breeding tube using a net, and transferred to water in an aerated $50 \mathrm{~L}$ plastic aquarium, to which anesthetic solution (clove oil containing 85\% eugenol; Sigma, USA) had been added. When a fish had become anesthetized, it was immediately transferred to a recovery tank. The time to achieve anesthesia (anesthesia time) and the recovery time were measured in seconds using a stopwatch. The anesthetic effects of clove oil were investigated at five concentrations $(10,20,30,60,90,120$ and $150 \mathrm{ppm})$; these were prepared using a stock solution of clove oil dissolved in $95 \%$ methanol (Sigma, USA) at a ratio of 1:10. The anesthesia time was measured from when the fish was placed in the anesthetic-containing water to when it was perfectly sedated and had minimal opercular movement (stage A6, Table 1), while the recovery time was measured from the time the fish was placed in the recovery tank to when it again exhibited normal swimming and responsiveness to visual stimulation (stage R6, Table 1). Table 1 is decision-based framework for categorizing anesthetic effects, derived from Park et al. (2011), and shows the stages of anesthesia and recovery that were used as endpoints in the present study, including A6 (minimal opercular movement only) and R6 (normal swimming, responsiveness to visual stimuli) (Summerfelt and Smith, 1990; Park et al., 2011). During the experiment the fish showed several stages in the development of anesthesia, including slowed swimming and side-to-side rolling (stage A2) through to opercular movement only and no reaction when it was flipped onto its other side (stage A6). At stage A6, individual fish were transferred to the recovery tank. Recovery was defined as the point at which erratic swimming began, and included the fish righting its balance and flipping itself back over when turned, (stage R5) and normal swimming, as well as responsiveness to visual stimuli (stage R6).

Table 1. Stages of anesthesia induction and recovery in clove oil efficacy tests performed in olive flounder, Paralichthys olivaceus

\begin{aligned} \hline \hline & \multicolumn{1}{c}{ Anesthesia } \\ \hline Stage & \multicolumn{1}{c}{ Characteristic behavior } \\ \hline A1 & Normal swimming, opercular movement and normal general movement \\ A2 & Swimming speed slowed, rolling from side to side \\ A3 & Partial loss of equilibrium, swimming erratic \\ A4 & Complete loss of equilibrium, swimming perfectly inside out, pectoral fin, pelvic fin and dorsal fin movement stop \\ A5 & Little sedation, anal fin and tail fin movement stop \\ A6 & Perfect sedation, only opercular movement, when flip the sample, no reaction observed \\ A7 & Opercular movement ceased \\ \hline & \\ \hline Stage & \\ R1 & Resume opercular movement \\ R2 & Preferential movement of pectoral fin and tail fin \\ R3 & Dorsal fin, pelvic fin and anal fin movement \\ R4 & Swimming perfectly inside out \\ R5 & Swimming erratic, recovery of balance, When flip the sample, observed to flip themselves \\ R6 & Normal swimming, responsiveness to visual stimuli \end{aligned}


To investigate the stress response of fish to anesthetic exposure, blood samples were extracted from five randomly selected fish prior to exposure $(0 \mathrm{~h})$, and at 1, 6, 12, 24, and $48 \mathrm{~h}$ following anesthetic treatment. The blood was transferred to capillary tubes and analyzed following centrifugation at $200 \times \mathrm{g}$ for $10 \mathrm{~min}$. The plasma was collected and stored at $-80^{\circ} \mathrm{C}$ (SW-UF-200 freezer; Samwon Freezing Engineering, Busan, Korea) until analyzed. The cortisol concentration in $50 \mu \mathrm{L}$ samples was measured using a cortisol radioimmunoassay kit (Coat-A-Count TKCO Cortisol RIA Kit; DPC, USA). The sample was added to $100 \mathrm{~mL}$ of antiserum and incubated for $45 \mathrm{~min}$ at $37^{\circ} \mathrm{C}$, then 1,000 $\mathrm{mL}$ of separation reagent was added. The mixture was placed in a refrigerator at $4{ }^{\circ} \mathrm{C}$ for $15 \mathrm{~min}$, then centrifuged at $1,200 \times \mathrm{g}$ for $15 \mathrm{~min}$. The supernatant was assayed using an automatic gamma radiation counter (Cobra; Packard, USA). The plasma glucose concentration was analyzed according to the method of Raabo \& Terkildsen (1960), using a glucose assay kit (Kit 510, Sigma, St Louis, MO, USA); the production of $\mathrm{H}_{2} \mathrm{O}_{2}$ by glucose oxidase in the presence of $o$-dianisidine was measured as an absorbance increase at $450 \mathrm{~nm}$. Blood lactic acid concentrations were analyzed using an automatic blood analyzer (Reflotron; Boehringer Mannheim, Germany).

At 10 days following analysis of the anesthetic effect and the stress response, the respiration of fish was assessed using a respirometer chamber comprising a sealed acrylic resin box having a wall thickness of $8 \mathrm{~mm}$ and overall dimensions of $10 \mathrm{~cm}$ (width) $\times 50 \mathrm{~cm}$ (length) $\times 10 \mathrm{~cm}$ (height). The hose providing inflow water to the respirometer was equipped with a temperature-controlled heater to maintain the water at $20 \pm 0.3^{\circ} \mathrm{C}$, cartridge filters $(10 \mu \mathrm{m}$ and $3 \mu \mathrm{m}$ ) to remove particles from the incoming water, and a flow-through ultraviolet lamp to reduce the likelihood of oxygen consumption by microbes. The water salinity was maintained optimum anesthetic salinity by brackish water, and optimum anesthetic salinity of each group were analyzed by anesthetic experiment. The respirometer chambers were prepared and labeled according to the measurement times and anesthetic concentrations.

To determine the most appropriate experimental concentrations of clove oil and lidocaine- $\mathrm{HCl}$, we performed a pilot experiment for $6 \mathrm{~h}$. To prevent mortality in the experimental sample, the anesthetized fish were maintained at several stages of anesthesia during the pilot study, ranging from normal swimming, opercular movement, and general movement (stage A1), to slow swimming and side-to-side rolling (stage A2) (Summerfelt and Smith, 1990; Park et al., 2011). The anesthetic effects of clove oil were determined at four concentrations: 0 (control), and 1, 2, and $3 \mathrm{ppm}$. Measurements were made at $1 \mathrm{~h}$ intervals over $6 \mathrm{~h}$ after the experiment commenced. Prior to measuring the dissolved oxygen (DO) concentration, the concentrations of $\mathrm{NH}_{4}^{+}$and $\mathrm{CO}_{2}$ were measured using a spectrophotometer (DR2800, $\mathrm{HACH}$, Loveland, Colorado, USA), and the respiration frequency (gill cover movement) of the fish was measured using a counter and a digital timer. The DO concentration was measured with an $\mathrm{O}_{2}$ electrode and a multi-data logger system (Oxyguard, Denmark).

One- and two-way analysis of variance (ANOVA) were performed for the data among treatments, and Duncan's test was performed when significant differences were found $(P<0.05$; SPSS statistics package SPSS 9.0; SPSS Inc., USA). All experiments were performed in triplicate. Unless otherwise stated, differences were considered to be statistically significant at $P<0.05$.

\section{RESULTS}

No samples of olive flounder, Paralichthys olivaceus died from stress as a result of exposure to the anesthetic during the experiment. Table 2 shows the results of a twoway ANOVA test for the effect of clove oil dose and water temperature on anesthesia. The exposure and recovery 
times were affected by the dose concentration of clove oil, and by water temperature. Table 3 shows the anesthetic effects of clove oil at each concentration and water temperature. The anesthesia time decreased significantly as both the concentration of clove oil and the water temperature increased. For each temperature, the anesthesia time decreased as the concentration of clove oil increased. Furthermore, at each concentration of clove oil, the anesthesia time decreased as water temperature increased. The recovery time at each temperature was affected by the clove oil concentration. The recovery time in each temperature increased significantly as the concentration of clove oil increased. In addition, the anesthesia time for each concentration of clove oil decreased as the water temperature increased. Thus, the recovery time at each temperature was related to changes in the concentration of clove oil, and the recovery time increased as water temperature increased. Based on an optimal anesthesia time of approximately $1 \mathrm{~min}$, the optimal concentrations of clove oil for olive flounder were $120 \mathrm{ppm}$ at $15^{\circ} \mathrm{C}$, and 90 ppm at $20^{\circ} \mathrm{C}$ and $25^{\circ} \mathrm{C}$. The ratio of the recovery time to the anesthetic exposure time, as a function of the concentration of clove oil and the water temperature, is shown in Fig. 1.

Table 2. Results of the two-way ANOVA for differences in clove oil dose and water temperature on anesthesia of olive flounder, Paralichthys olivaceus

\begin{tabular}{cccccc}
\hline \hline & \multicolumn{5}{c}{ Exposure time (sec) } \\
\hline Dose & 1 & Anova SS & Mean square & $F$-value & $P$-value \\
\hline Temperature & 3 & $1,489,907.0$ & $188,361.5$ & 190.2 & $<0.0001$ \\
Interaction & 7 & $1,568,742.2$ & $297,981.3$ & 300.9 & $<0.0001$ \\
\hline Dose & & & $306,342.1$ & 312.4 & $<0.0001$ \\
\hline Temperature & 1 & $236,841.0$ & $158,349.7$ & 156.7 & $<0.0001$ \\
Interaction & 7 & $1,564,871.0$ & $301,683.9$ & 300.9 & $<0.0001$ \\
\hline
\end{tabular}

Results of clove oil dose and water temperature on anesthesia among olive flounder were shown in Table 3.

Table 3. Effects of clove oil dose and water temperature on anesthesia of olive flounder, Paralichthys olivaceus

\begin{tabular}{|c|c|c|c|c|c|c|}
\hline \multirow{2}{*}{$\begin{array}{c}\text { Dose } \\
\left(\mathrm{mgL}^{-1}\right)\end{array}$} & \multicolumn{3}{|c|}{ Exposure time (sec) } & \multicolumn{3}{|c|}{ Recovery time (sec) } \\
\hline & $15^{\circ} \mathrm{C}$ & $20^{\circ} \mathrm{C}$ & $25^{\circ} \mathrm{C}$ & $15^{\circ} \mathrm{C}$ & $20^{\circ} \mathrm{C}$ & $25^{\circ} \mathrm{C}$ \\
\hline 10 & $173 \pm 14.9$ & $163 \pm 19.9$ & $153 \pm 25.5$ & $117 \pm 57.7$ & $91 \pm 25.7$ & $67 \pm 12.4$ \\
\hline 20 & $164 \pm 7.9$ & $148 \pm 14.3$ & $121 \pm 13.6$ & $140 \pm 19.2$ & $126 \pm 27.9$ & $119 \pm 15.2$ \\
\hline 30 & $155 \pm 21.2$ & $119 \pm 6.5$ & $112 \pm 8.1$ & $160 \pm 29.5$ & $152 \pm 18.4$ & $131 \pm 7.9$ \\
\hline 60 & $107 \pm 26.7$ & $88 \pm 15.1$ & $77 \pm 19.3$ & $334 \pm 21.5$ & $224 \pm 18.7$ & $207 \pm 16.6$ \\
\hline 90 & $79 \pm 10.2$ & $63 \pm 1.7$ & $58 \pm 2.4$ & $468 \pm 35.7$ & $435 \pm 10.8$ & $395 \pm 14.2$ \\
\hline 120 & $65 \pm 3.9$ & $52 \pm 1.5$ & $46 \pm 2.1$ & $555 \pm 31.5$ & $530 \pm 14.2$ & $519 \pm 19.6$ \\
\hline 150 & $60 \pm 8.3$ & $47 \pm 8.0$ & $42 \pm 4.6$ & $960 \pm 22.9$ & $676 \pm 17.1$ & $630 \pm 20.5$ \\
\hline
\end{tabular}

Each value is mean \pm standard deviation $(n=20)$. Values in the same column not sharing common superscripts are significantly different $(P<0.05)$. 


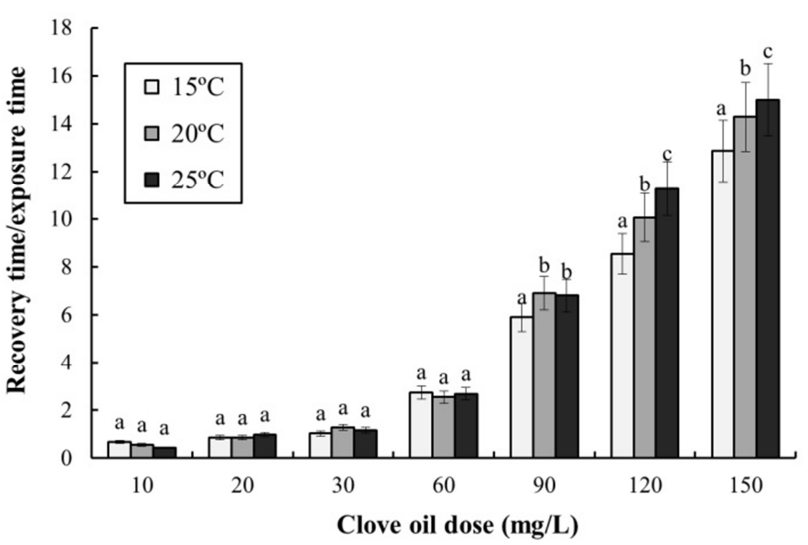

Fig. 1. Effect of clove oil dose and water temperature on recovery time/exposure time ratio in olive flounder, Paralichthys olivaceus. Different letters on the bars indicate statistical significance $(P<0.05)$.

The recovery time/exposure time ratio gradually increased as the clove oil concentration increased in each water temerature treatment. At $90 \mathrm{ppm}, 120 \mathrm{ppm}$, and $150 \mathrm{ppm}$, the ratio increased significantly as water temperature increased; however, at other concentrations the ratio showed no clear relationship with water temperature.

Fig. 2 shows the stress response of the fish to clove oil anesthesia over $48 \mathrm{~h}$. The plasma cortisol concentration at each temperature increased significantly up to $12 \mathrm{~h}$. After $1 \mathrm{~h}$ of exposure the plasma cortisol concentrations were 8 $\pm 1.4,10 \pm 1.0$, and $14 \pm 1.3 \mu \mathrm{g} / \mathrm{dL}$ at $15^{\circ} \mathrm{C}, 20^{\circ} \mathrm{C}$, and $25^{\circ} \mathrm{C}$, respectively. After $6 \mathrm{~h}$ the plasma cortisol concentrations were $18 \pm 1.0,23 \pm 1.2$, and $30 \pm 1.3 \mu \mathrm{g} / \mathrm{dL}$ at $15^{\circ} \mathrm{C}, 20^{\circ} \mathrm{C}$, and $25^{\circ} \mathrm{C}$, respectively. Thus, the rate of increase in the plasma cortisol concentration increased with increasing water temperature up to $12 \mathrm{~h}$. After this time point, the cortisol concentration at each temperature decreased significantly to $48 \mathrm{~h}$. At $12 \mathrm{~h}$ the plasma cortisol concentrations were $35 \pm 1.7,36 \pm 1.8$, and $35 \pm 1.4 \mu \mathrm{g} / \mathrm{dL}$ at $15^{\circ} \mathrm{C}, 20^{\circ} \mathrm{C}$, and $25^{\circ} \mathrm{C}$, respectively, while at $24 \mathrm{~h}$ were $20 \pm 2.4,13 \pm$ 3.0 , and $10 \pm 1.7 \mu \mathrm{g} / \mathrm{dL}$, and at $48 \mathrm{~h}$ were $5 \pm 0.6,2 \pm 0.5$, and $1 \pm 0.4 \mu \mathrm{g} / \mathrm{dL}$, respectively. Thus, the rate of decrease in the plasma cortisol concentration increased as the water temperature increased.

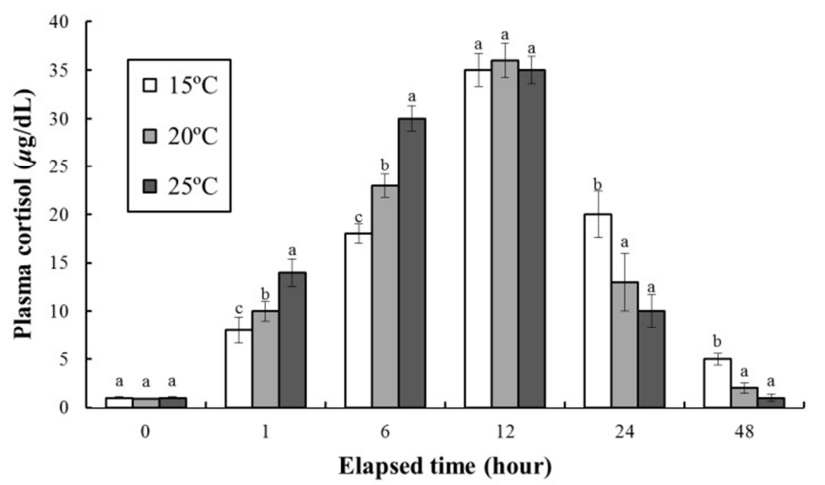

Fig. 2. Variations in the plasma cortisol concentrations in the blood plasma of the olive flounder, Paralichthys olivaceus during 48 hours of various temperatures in anesthetic groups. Exposure dose of clove oil were $90 \mathrm{ppm}$ in each group. Values are means $\pm \mathrm{SE}$ of triplicate experiments $(n=20)$. Actually $n=20$ for each experiment because the means and SE were calculated separately for each group. Different letters on error bars are significantly different among elapsed time in anesthesia groups $(P<0.05)$.

The DO concentrations, respiratory frequencies, $\mathrm{pH}$ values, and $\mathrm{NH}_{4}^{+}$and $\mathrm{CO}_{2}$ concentrations in the clove oil treatments are shown in Tables 4 and 5, and Figs. 3, 4, and 5, respectively. The DO concentration, $\mathrm{pH}$ value, and the respiratory frequency decreased in all experimental groups up to $6 \mathrm{~h}$ (Table 4 and Figs. 3 and 4), whereas the $\mathrm{NH}_{4}^{+}$ and $\mathrm{CO}_{2}$ concentrations increased in all experimental groups (Table 5 and Fig. 5). Over this period the $\mathrm{pH}$ value and DO concentrations increased with increasing clove oil concentration. At all measurement times the DO concentration in all clove oil treatments was higher than in the control group (Table 4). At $6 \mathrm{~h}$ the $\mathrm{pH}$ values were $6.1 \pm 0.064,6.35 \pm$ $0.068,6.57 \pm 0.061$, and $6.82 \pm 0.066$ in the control group and the 1,2 and 3 ppm clove oil treatments, respectively, and $\mathrm{pH}$ values in all clove oil treatments were significantly higher than that of control group (Fig. 4). The $\mathrm{CO}_{2}$ and $\mathrm{NH}_{4}{ }^{+}$concentrations and the respiratory frequencies decreased with increasing clove oil concentration $(P<0.05)$. At $6 \mathrm{~h}$ the respiratory frequencies were markedly less than in the control group $(23 \pm 1.9,23 \pm 1.5,23 \pm 1.4$, and $42 \pm 3.4$, 
Table 4. Change of dissolved oxygen concentrations during clove-oil-induced sedation of olive flounder, Paralichthys olivaceus in a simulated transport experiment

\begin{tabular}{ccccc}
\hline \hline \multirow{2}{*}{$\begin{array}{c}\text { Time } \\
\text { (hour) }\end{array}$} & \multicolumn{3}{c}{ DO $(\mathrm{mg} / \mathrm{L})$} \\
\cline { 2 - 5 } & Control & $1 \mathrm{ppm}$ & $2 \mathrm{ppm}$ & $3 \mathrm{ppm}$ \\
\hline 0 & $7.5 \pm 0.32^{\mathrm{a}}$ & $7.5 \pm 0.32^{\mathrm{a}}$ & $7.5 \pm 0.32^{\mathrm{a}}$ & $7.5 \pm 0.32^{\mathrm{a}}$ \\
1 & $6.4 \pm 0.26^{\mathrm{a}}$ & $6.5 \pm 0.23^{\mathrm{a}}$ & $6.9 \pm 0.24^{\mathrm{b}}$ & $6.9 \pm 0.25^{\mathrm{b}}$ \\
2 & $5.9 \pm 0.22^{\mathrm{a}}$ & $6.1 \pm 0.23^{\mathrm{b}}$ & $6.2 \pm 0.19^{\mathrm{b}}$ & $6.1 \pm 0.20^{\mathrm{b}}$ \\
3 & $4.9 \pm 0.24^{\mathrm{a}}$ & $5.0 \pm 0.24^{\mathrm{a}}$ & $5.3 \pm 0.21^{\mathrm{b}}$ & $5.2 \pm 0.22^{\mathrm{b}}$ \\
4 & $4.1 \pm 0.20^{\mathrm{a}}$ & $4.4 \pm 0.2^{\mathrm{b}}$ & $4.7 \pm 0.29^{\mathrm{c}}$ & $4.8 \pm 0.23^{\mathrm{c}}$ \\
5 & $3.7 \pm 0.21^{\mathrm{a}}$ & $3.9 \pm 0.18^{\mathrm{b}}$ & $4.1 \pm 0.22^{\mathrm{c}}$ & $4.1 \pm 0.19^{\mathrm{c}}$ \\
6 & $3.1 \pm 0.19^{\mathrm{a}}$ & $3.5 \pm 0.20^{\mathrm{b}}$ & $3.8 \pm 0.17^{\mathrm{c}}$ & $3.9 \pm 0.18^{\mathrm{c}}$ \\
\hline
\end{tabular}

The values are means of triplicate groups $(n=20)$. Values in the same column not sharing common superscripts are significantly different $(P<0.05)$.

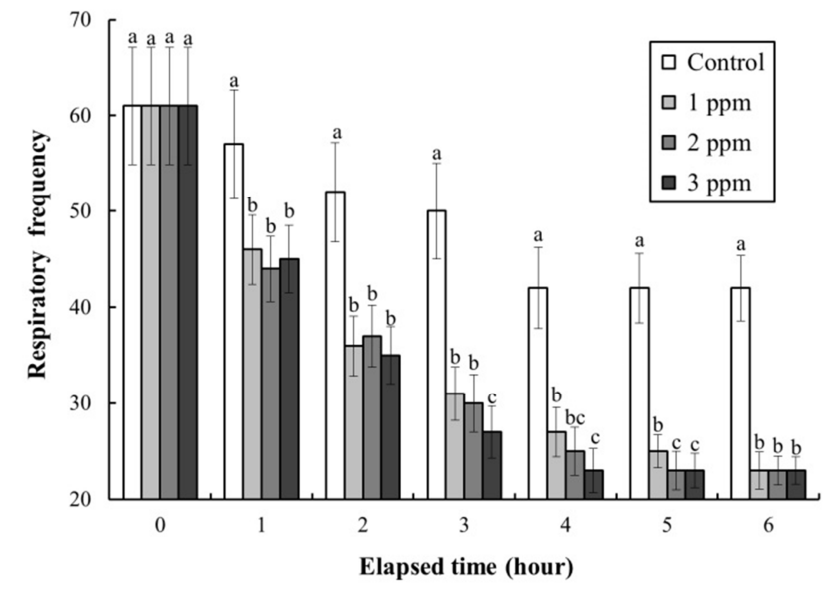

Fig. 3. Change of respiratory frequency (gill cover movement) during clove-oil-induced sedation of olive flounder, Paralichthys olivaceus in a simulated transport exeriment. Values are means $\pm \mathrm{SE}$ of triplicate experiments $(n=20)$. Actually $n=20$ for each experiment because the means and SE were calculated separately for each group. Different letters on error bars are significantly different between no anesthesia and clove oil anesthesia groups $(P<0.05)$.

respectively; Fig. 3). The $\mathrm{CO}_{2}$ concentration in the 1, 2, and 3 ppm clove oil treatments were lower than that in the control group (Table 5). With respect to $\mathrm{NH}_{4}^{+}$, at all measurement times the concentrations in the 1,2 , and 3 ppm clove oil treatments were lower than that in the

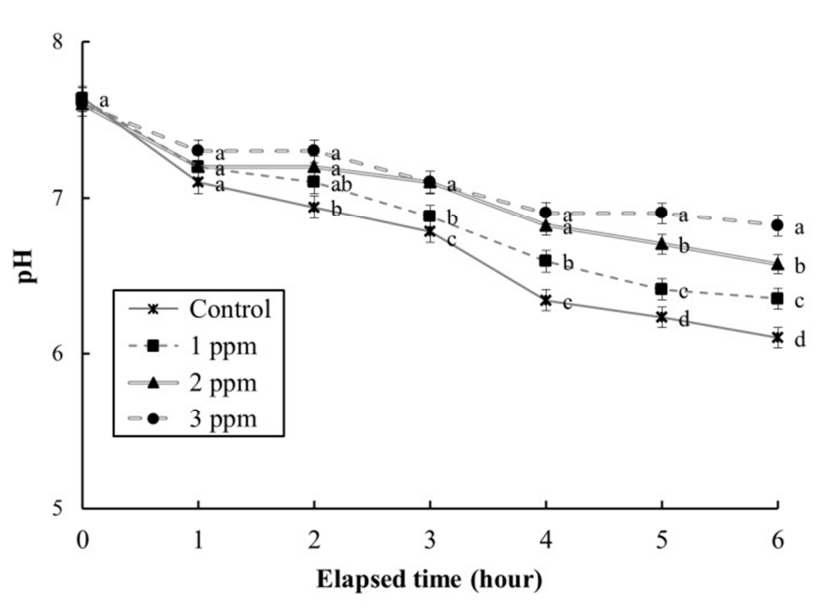

Fig. 4. Change of $\mathrm{pH}$ values during clove-oil-induced sedation of olive flounder, Paralichthys olivaceus in a simulated transport experiment. Values are means $\pm \mathrm{SE}$ of triplicate experiments $(n=20)$. Actually $n=20$ for each experiment because the means and SE were calculated separately for each group. Different letters on error bars are significantly different between no anesthesia and clove oil anesthesia groups $(P<0.05)$.

control group $(0.07 \pm 0.006,0.06 \pm 0.009,0.05 \pm 0.005$, and $0.09 \pm 0.007 \mathrm{mg} / \mathrm{L}$, respectively).

\section{DISCUSSION}

Determining the safety and reliability of anesthetics, and 
Table 5. Change of carbon dioxide $\left(\mathrm{CO}_{2}\right)$ concentrations during clove-oil-induced sedation of olive flounder, Paralichthys olivaceus in a simulated transport experiment

\begin{tabular}{ccccc}
\hline \hline \multirow{2}{*}{$\begin{array}{c}\text { Time } \\
\text { (hour) }\end{array}$} & \multicolumn{3}{c}{$\mathrm{CO}_{2}(\mathrm{mg} / \mathrm{L})$} \\
\cline { 2 - 5 } & Control & $1 \mathrm{ppm}$ & $2 \mathrm{ppm}$ & $3 \mathrm{ppm}$ \\
\hline 0 & $0.0^{\mathrm{a}}$ & $0.0^{\mathrm{a}}$ & $0.0^{\mathrm{a}}$ & $0.0^{\mathrm{a}}$ \\
1 & $12.5 \pm 2.14^{\mathrm{a}}$ & $12.1 \pm 1.89^{\mathrm{a}}$ & $11.6 \pm 1.46^{\mathrm{a}}$ & $11.9 \pm 2.03^{\mathrm{a}}$ \\
2 & $20.0 \pm 2.37^{\mathrm{c}}$ & $18.2 \pm 2.42^{\mathrm{b}}$ & $17.5 \pm 1.98^{\mathrm{a}}$ & $16.3 \pm 2.32^{\mathrm{a}}$ \\
3 & $28.7 \pm 2.72^{\mathrm{b}}$ & $27.3 \pm 2.78^{\mathrm{b}}$ & $24.3 \pm 2.38^{\mathrm{a}}$ & $25.7 \pm 2.84^{\mathrm{a}}$ \\
4 & $32.3 \pm 2.98^{\mathrm{c}}$ & $30.2 \pm 2.56^{\mathrm{b}}$ & $27.1 \pm 2.45^{\mathrm{a}}$ & $27.4 \pm 3.15^{\mathrm{a}}$ \\
5 & $33.6 \pm 3.12^{\mathrm{c}}$ & $31.8 \pm 3.08^{\mathrm{b}}$ & $29.8 \pm 2.92^{\mathrm{a}}$ & $28.9 \pm 3.36^{\mathrm{a}}$ \\
6 & $37.5 \pm 3.68^{\mathrm{c}}$ & $34.4 \pm 3.34^{\mathrm{b}}$ & $32.7 \pm 2.96^{\mathrm{a}}$ & $31.3 \pm 3.52^{\mathrm{a}}$ \\
\hline
\end{tabular}

The values are means of triplicate groups $(n=20)$. Values in the same column not sharing common superscripts are significantly different $(P<0.05)$.

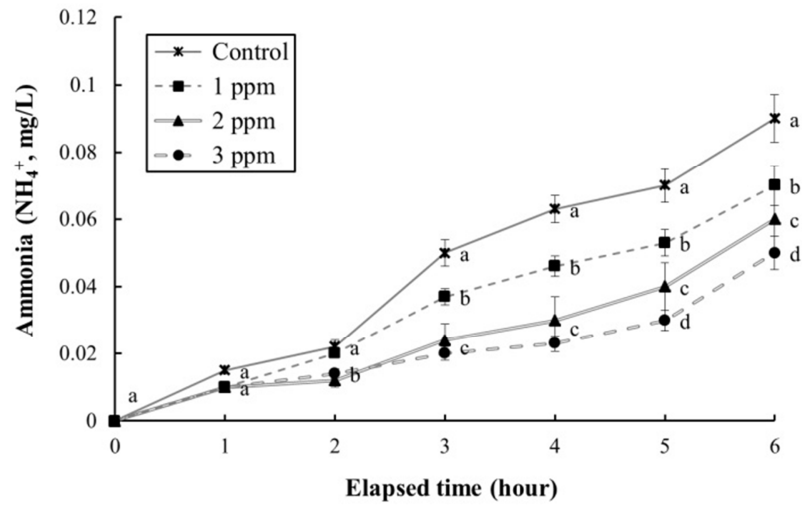

Fig. 5. Change of Ammonia $\left(\mathrm{NH}_{4}{ }^{+}\right)$values during cloveoil-induced sedation of olive flounder, Paralichthys olivaceus in a simulated transport experiment. Values are mean \pm SE of triplicate experiments $(n=$ 20 ). Actually $n=20$ for each experiment because the means and SE were calculated separately for each group. Different letters on error bars are signifiantly different between no anesthesia and clove oil anesthesia groups $(P<0.05)$.

the associated recovery time, is a prerequisite for choosing the most appropriate anesthetic for a given species. The anesthesia time is the time required for an animal to reach the anesthetized condition for the species, and the recovery time is the time required for the animal to completely recover (Summerfelt \& Smith, 1990). The results of this study indicated that clove oil is an effective anesthetic for $P$. olivaceus. Based on the criteria that anesthesia should be achieved within $3 \mathrm{~min}$, that recovery should occur in $<$ $10 \mathrm{~min}$, and that no mortality occur (Park et al., 2011), we assessed a range of concentrations of clove oil (10-120 ppm) and exposure water temperatures of $20^{\circ} \mathrm{C}$ and $25^{\circ} \mathrm{C}$.

Our results clearly indicated that shorter anesthesia times were achieved with higher concentrations of clove oil. The observed anesthesia times for olive flounder, Paralichthys olivaceus exposed to clove oil were similar to previous reports of its effect on other bony fishes including sockeye salmon, Oncorhynchus nerka, rock bream, Oplegnthus fasciatus, and kelp grouper, Epinephelus bruneus (Woody et al., 2002; Park et al., 2008 and 2009b). The dose response curves for olive flounder exposed to clove oil were negatively exponential, with higher doses resulting in reduced times to anesthesia stage A6 (see Table 1). Optimum anesthetic concentrations are usually expected to induce anesthesia within $3 \mathrm{~min}$, with recovery occurring within 10 min (Park et al., 2011). We set the optimum anesthesia concentration at approximately $1 \mathrm{~min}$, and at this level found that the optimal clove oil concentrations for olive flounder were $120 \mathrm{ppm}$ at $15^{\circ} \mathrm{C}$, and $90 \mathrm{ppm}$ at $20^{\circ} \mathrm{C}$ or $25^{\circ} \mathrm{C}$. For other species the optimal clove oil concentration 
for achieving an anesthesia time of approximately $1 \mathrm{~min}$ include $80 \mathrm{ppm}$ at $9.4^{\circ} \mathrm{C}$ for sockeye salmon, $150 \mathrm{ppm}$ at $24^{\circ} \mathrm{C}$ and $100-125 \mathrm{ppm}$ at $26^{\circ} \mathrm{C}$ for rock bream, and 50 $100 \mathrm{ppm}$ at $22^{\circ} \mathrm{C}$ for kelp grouper (Woody et al., 2002; Park et al., 2008 and 2009b).

At each clove oil concentration, anesthesia occurred faster at higher water temperatures. The relationship between water temperature and anesthesia time followed a negative exponential curve, with increasing water temperature resulting in decreased anesthesia time. A similar inverse relationship has also been reported in studies of anesthesia by clove oil in other fish species, including European sea bass, Dicentrarchus labrax and gilthead sea bream, Sparus aurata (Constantinos et al., 2005). For these species, lower temperatures resulted in significantly longer induction of anesthesia and recovery times (Constantinos et al., 2005). In addition, kelp grouper anesthetized with clove oil, and greenling, Hexagrammos decagrammus anesthetized with lidocaine- $\mathrm{HCl}$ exhibited similar trends (Park et al., 2003; Constantinos et al., 2005; Park et al., 2008). Park et al. (1988) reported an anesthesia time of $93.0 \pm 7.5 \mathrm{~s}$ for olive flounder at $100 \mathrm{ppm}$ lidocaine- $\mathrm{HCl}$, and that the optimum concentration of lidocaine- $\mathrm{HCl}$ was 200 ppm. Comparison of the anesthetic potency of clove oil and lidocaine-HCl showed that olive flounder were more sensitive to clove oil than to lidocaine-HCl; clove oil more effectively immobilized fish at lower doses than did lidocaine- $\mathrm{HCl}$ in the same anesthesia time.

If the ratio of the recovery time to the anesthesia time is greater than 1 , the recovery time is longer than the anesthesia time. At each water temperature in our study, the ratio of the recovery time to the anesthesia time increased as the anesthesia concentration increased. That is, as the anesthetic concentration increased, the increase in the recovery time was greater than the decrease in the anesthesia time. Our study belongs to this trend. In contrast, as the anesthesia concentration was reduced, the rate of decrease in the recovery time was greater than the rate of increase in the anesthesia time. Similar results demonstrating proportional changes in the clove oil concentration and the ratio of the recovery time to the anesthesia time have been reported for rock bream (Park et al., 2009b).

Cortisol is an indicator of a stress response in fish subject to various stressors, and is involved in metabolism and ecologic balance (Mommsen et al., 1999). In addition, cortisol affects the body balance, carbohydrates, proteins, and lipids (Mommsen et al., 1999). Cortisol levels in fish suggest that anesthesia, salinity, $\mathrm{DO}, \mathrm{pH}, \mathrm{NH}_{4}{ }^{+}$, and acidic conditions can affect fish metabolism and hormone levels (Mommsen et al., 1999). Plasma cortisol concentrations were controlled in the study of Mommsen et al. (1999), it means they made the annually changeable temperature, fresh water to sea water, salinity, waste water and DO. Plasma cortisol is recognized as a useful indicator of stress in fish (Schreck, 1982; Park et al., 2008). Elevated plasma cortisol levels were reported in red drum (Sciaenops ocellatus) simultaneously exposed to the anesthetics MS222 and quinaldine (Massee et al., 1995). Barton \& Iwama (1991) stated that "Usually, phenomenon that plasma cortisol concentration of fishes rises by stress is first order reaction, phenomenon that plasma glucose concentration rises is result of second-order first order reaction by hormone rise reaction by stress." The plasma cortisol concentration in anesthetized olive flounder returned to approximately the concentration in control fish $48 \mathrm{~h}$ post-administration of clove oil. This result is similar to that reported by Park et al. (2008).

The anesthesia and recovery times were fastest at $25^{\circ} \mathrm{C}$. Anesthesia of fish is accomplished through the gills. High metabolism causes rapid respiration. If the metabolic rate is high, the anesthetic is absorbed more rapidly through the gills (Summerfelt \& Smith, 1990). The metabolism of olive flounder at $25^{\circ} \mathrm{C}$ was expected to be higher than at the other temperatures tested. The results showed that the 
anesthesia and recovery times at $25^{\circ} \mathrm{C}$ were faster than at the other temperatures tested. To confirm and interpret these observations, comparative physiology studies will need to be undertaken.

The patterns of decline in the DO concentration in water in the control, clove oil, and lidocaine- $\mathrm{HCl}$ treatments were consistent with the trends reported in studies of the amur minnow, Rhynchocypris steindachneri and winter flounder, Pleuronectes americanus (Park et al., 1998 and 2009a). These results suggest that high levels of stress induced by handling or netting cause high levels of oxygen consumption during the early stages of transportation. The results of this study are similar to those reported by Ferreira et al. (1984), who used benzocaine- $\mathrm{HCl}$ as an anesthetic in the transport of Java tilapia, Oreochromis mossambicus. In general, both studies showed that following application of the anesthetic there was a reduction in fish metabolism, which is an indication of declining oxygen consumption. In this study there appeared to be a positive relationship between the concentration of clove oil and the DO concentration, insofar as the group treated with the highest concentration of clove oil exhibited the smallest decline in DO (Ferreira et al., 1984). In a similarly designed experiment by Park et al. (1998), involving amur minnow as the test organism, the same trends in DO concentration and ventilation rates was observed over $2 \mathrm{~h}$ as were observed over $6 \mathrm{~h}$ in our study. Park et al. (1998) used lower lidocaine-HCl concentrations $(5,10$, and $20 \mathrm{ppm})$ and a lower temperature $\left(18^{\circ} \mathrm{C}\right.$, compared with $26^{\circ} \mathrm{C}$ in this experiment), but nearly identical trends were found. This is an important comparison because it indicates the wide-ranging effects of clove oil over a broad spectrum of temperatures.

Guo et al. (1995) performed a transportation experiment that involved the playfish, Xiphophorus maculatus (Günther) being treated with three anesthetics: 2-phenoxyethanol (200 ppm), quinaldine sulfate (10 ppm), and MS-222 (30 ppm). At $16 \mathrm{~h}$ following anesthetic administration the
$\mathrm{NH}_{4}^{+}$concentration in the water in the 2-phenoxyethanol treatment was only $65 \%$ that in the control, $20 \%$ that in the quinaldine sulfate treatment, and relatively lower than in the MS-222 treatment. The trends in $\mathrm{NH}_{4}{ }^{+}$concentrations exhibited by the five experimental groups were consistent with the trends reported by Park et al. (1998 and 2009a) and Guo et al. (1995). Our conclusions are consistent with those of Park et al. (1998 and 2009a), insofar as the overall reduction in $\mathrm{NH}_{4}^{+}$excretion was directly related to the anesthetic-induced decline in metabolism.

This study showed that clove oil is effective for anesthetizing olive flounder, and that the anesthetic effect was influenced by water temperature. Park et al. (2011) reported that the anesthetic effects of clove oil or lidocaine- $\mathrm{HCl}$ were significantly affected by water temperature and the anesthetic concentration, decreasing proportionately as these parameters increased. The results of Park et al. (2011) suggest that the anesthetic effects of clove oil are similar to those of lidocaine-HCl. The results of our experiment suggest that clove oil reduced the metabolic activity of olive flounder, thus reducing excretion of $\mathrm{NH}_{4}^{+}$and oxygen consumption by the fish. Clove oil is a cost-effective and efficient anesthetic, and is safe for use and non-toxic to the fish or users (Park et al., 2003). In conclusion, clove oil is an effective anesthetic for use in improving the transport of olive flounder and minimizing the stress for olive flounder. The results of this study will improve the safe laboratory handling and transport of olive flounder, which are commonly required for use in research studies and experiments. The results of our study should also be useful for aquaculturalists and fish transporters wanting to minimize the stress imposed on fish during transport.

\section{ACKNOWLEDGEMENTS}

This research was supported by Development of King Nupchi Polyploid Seed for Export (213004-04-4-1SB220): 
the Ministry of Aquaculture, Food and Rural Affairs (MAFRA); the Ministry of Oceans and Fisheries (MOF); the Rural Development Administration (RDA); and the Korea Forest Service (KFS). It was also supported by the Fishery Genetics and Breeding Sciences Laboratory, Korea Maritime and Ocean University, Korea. The comments of the anonymous reviewers greatly improved the quality of the manuscript. All experiments in this study complied with the current laws of Korea (the Law Regarding Experimental Animals, No. 9932) and the Ethical Guidelines of Pukyung National University, Korea.

\section{REFERENCES}

Barton BA, Iwama GK (1991) Physiological changes in fish from stress in aquaculture with emphasis on the response and effects of corticosteroids. Annu Rev Fish Dis 1:3-26.

Carmichael GJ, Tomasso JR (1988) Survey of fish transportation equipment and techniques. Prog Fish-Cultur 50:155-159

Carmichael GJ, Tomasso JR, Simco BA, Davis KB (1984) Characterization and alleviation of stress associated with hauling largemouth bass. Trans Amer Fisher Soc 113:778-785.

Constantinos CM, Gloriana C, Irini S, Alberta PM (2005) Comparative efficacy of clove oil and 2-phenoxyethanol as anesthetics in the aquaculture of European sea bass (Dicentrarchus labrax) and gilthead sea bream (Sparus aurata) at different temperatures. Aquaculture 246: 467-481.

Ferreira JT, Schoonbee HJ, Smith GL (1984) The use of benzocaine-hydrochloride as an aid in the transport of fish. Aquaculture 42: 169-174.

Grizzle JM, Mauldin AC, Young D Henderson E (1985) Survival of juvenile striped bass (Morone saxatilis) and Morone hybrid bass (Morone crysops $\times$ Morone saxatilis) increased by addition of calcium to soft water. Aquaculture 46: 167-171.

Guo F-C, Teo L-H, Chen T-W (1995) Effects of anaesthetics on the water parameters in simulated transport experiment of playfish, Xiphophorus maculatus (Günther). Aquacult Res 26:265-271.

Han KH, Kim K-S, Lee S-H (2007) Morphological studies on the digestive tracts of the larvae and juveniles of the flounder, Paralichthys olivaceus. Dev Reprod 11:121125 (in Korean with English abstract).

Hur JW, Park I-S, Chang YJ (2007) Physiological responses of the olive flounder, Paralichthys olivaceus, to a series stress during the transportation process. Ichthyol Res 54:32-37.

Massee KC, Rust MB, Hardy RW, Stickney RR (1995) The effectiveness of tricaine, quinaldine sulfate and metomidate as anesthetics for larval fish. Aquaculture 134:351-359.

Mommsen TP, Vijayan MM, Moon TW (1999) Cortisol in teleosts: Dynamics, mechanisms of action and metabolic regulation. Rev Fish Biol Fisher 9:211-268.

Park I-S, Gil HW, Yoo GY, Oh JS (2015) Effects of starvation in rock bream, Oplegnathus fasciatus and olive flounder, Paralichthys olivaceus. Dev Reprod 19:97-109.

Park I-S, Hur JW, Choi JW (2012) Hematological responses, survival, and respiratory exchange in the olive flounder, Paralichthys olivaceus, during starvation. Asian-Aust J Anim Sci 25:1276-1284.

Park I-S, Jo JH, Lee SJ, Kim YA, Kim KE, Hur JW, Yoo JS, Song YC (2003) Anaesthetic effect of lidocaine hydrochloride-sodium bicarbonate and MS-222 on the greenling (Hexagrammos otakii). J Kor Fish Soc 36: 449-453.

Park I-S, Kim J-M, Kim YH, Kim DS (1988) Influence of lidocaine as an anaesthetic for marine fishes. J Fish Pathol 1:123-130 (in Korean with English abstract).

Park I-S, Lim CH, Choi MS (1998) The evaluation of 
lidocaine-hydrochloride as anaesthetic for the transportation of Rhynchocypris steindachneri. J Kor Fish Soc 31: 785-790 (in Korean with English abstract).

Park I-S, Park MO, Hur JW, Kim DS, Chang YJ, Kim YJ, Park JY, Johnson SC (2009a) Anesthetic effects of lidocaine-hydrochloride on water parameters in simulated transport experiment of juvenile winter flounder, Pleuronectes americanus. Aquaculture 294:76-79.

Park I-S, Park SJ, Gil HW, Nam YK, Kim DS (2011) Anesthetic effects of clove oil and lidocaine- $\mathrm{HCl}$ on marine medaka, Oryzias dancena. Lab Animal 40:4551.

Park MO, Hur WJ, Im SY, Seol DS, Lee JH, Park I-S (2008) Anaesthetic efficacy and physiological responses to clove oil-anaesthetized kelp grouper Epinephelus bruneus. Aquacult Res 39:877-884.

Park MO, Im S-Y, Seol D-W, Park I-S (2009b) Efficacy and physiological responses of rock bream (Oplegnathus fasciatus) to anesthetization with clove oil. Aquaculture 287:427-430.

Raabo E, Terkildsen TC (1960) On the enzymatic determination of blood glucose. Scandin J Clinic Lab Invest 12:
402-407.

Schreck CB (1982) Stress and rearing of Salmonids. Aquaculture 28:241-249.

Sladky KK, Swanson CR, Stoskopf MK, Loomis MR, Lewbart GA (2001) Comparative efficacy of tricaine methanesulfonate and clove oil for use as anesthesia in red pacu (Piaractus brachypomus). Am J Vet Res 62:337-342.

Staurnes M, Sigholt T, Pedersen HP, Rustad T (1994) Physiological effects of simulated high-density transport of Atlantic cod (Gadus morhua). Aquaculture 119: 381-391.

Summerfelt RC, Smith LS (1990) Anesthesia, surgery, and related techniques. In: Methods for Fish Biology, American Fisheries Society, Bethesda, MD, USA, pp 213-272.

Tomasso JR, Davis KB, Parker NC (1980) Plasma corticosteroid and electrolyte dynamics of hybrid striped bass (white bass $\times$ striped bass) during netting and hauling stress. Proceed World Maricult Soc 11:303-310.

Woody CA, Nelson J, Ramstad K (2002) Clove oil as an anesthetic for adult sockeye salmon (Oncorhynchus nerka): field trials. J Fish Biol 60:340-347. 